\title{
Effect of shackling, electrical stunning and halal slaughtering method on stress- linked hormones in broilers
}

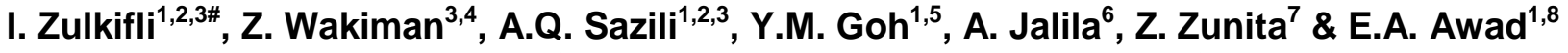 \\ ${ }^{1}$ Institute of Tropical Agriculture and Food Security, Universiti Putra Malaysia, 43400 UPM Serdang, Selangor, Malaysia \\ ${ }^{2}$ Department of Animal Science, Universiti Putra Malaysia, 43400 UPM Serdang, Selangor, Malaysia \\ ${ }^{3}$ Halal Products Research Institute, Universiti Putra Malaysia, 43400 UPM Serdang, Selangor, Malaysia \\ ${ }^{4}$ Negeri Sembilan Veterinary Services Department, 71770 Seremban, Negeri Sembilan Malaysia \\ ${ }^{5}$ Department of Veterinary Preclinical Sciences, University Putra Malaysia, 43400 UPM Serdang, Selangor, Malaysia \\ ${ }^{6}$ Department of Veterinary Clinical Studies, Universiti Putra Malaysia, 43400 UPM Serdang, Selangor, Malaysia G6 \\ ${ }^{7}$ Department of Veterinary Pathology and Microbiology, Universiti Putra Malaysia, 43400 UPM Serdang, Selangor, \\ Malaysia \\ ${ }^{8}$ Department of Poultry Production, University of Khartoum, Khartoum North 13314, Sudan
}

(Received 10 July 2018; Accepted 1 January 2019; First published online 23 June 2019)

\author{
Copyright resides with the authors in terms of the Creative Commons Attribution 4.0 South African Licence. \\ See: http://creativecommons.org/licenses/by/4.0/za \\ Condition of use: The user may copy, distribute, transmit and adapt the work, but must recognise the authors and \\ the South African Journal of Animal Science.
}

\begin{abstract}
The objective of this study was to evaluate the effect of shackling and halal slaughter with head-only electrical stunning (ES) using water bath or no stunning (NS) on plasma levels of adrenaline (AD), noradrenaline (NAD) and corticosterone (CORT) levels of broiler chickens. Male and female broiler chickens (Cobb 500) 38 days old from a commercial farm in Johore, Malaysia, were placed in plastic crates $(0.80 \times$ $0.60 \times 0.31 \mathrm{~m})$ at 10 birds per crate, and transported for 2.5 hours in an open truck. The ambient temperature during transportation was 25 to $27^{\circ} \mathrm{C}$. Upon arrival at a commercial processing plant, a total of 50 male broiler chickens $(2.2-2.5 \mathrm{~kg})$ were randomly selected from the flocks that were delivered, transferred to different five crates (10 birds per crate) and held in a lairage for 2 to $3 \mathrm{~h}$. Blood samples were collected at various points, namely after lairaging (P1) (first sampling point for both ES and NS chickens, regarded as basal values), shackling (P2) (second sampling point for both ES and NS chickens), stunning (P3) (third sampling point for ES chickens), and ventral neck incision in stunned (P4) (fourth sampling point for ES chickens) and no stun (P5) (third sampling point for NS chickens). Ten birds were sampled at each sampling point (50 birds in total). Both stunned and no stun birds were shackled. Results show that shackling (P2) did not significantly affect the AD, NAD and CORT levels. However, electrical stunning elevated both the $A D$ and CORT levels significantly, but not NAD. Neck cut had negligible effect on the AD and NAD in NS and ES broilers, but significantly increased CORT compared with the basal CORT value. In conclusion, the study demonstrated that head-only electrical stunning using a water bath might elevate $A D$ and CORT. The study concluded that, as measured by AD and NAD, slaughter with or without stunning may not induce a physiological stress response in broilers.
\end{abstract}

Keywords: corticosterone, adrenaline, noradrenaline, primary processing, poultry

\#Corresponding author: zulidrus@upm.edu.my

\section{Introduction}

Animal slaughter for food purposes is a delicate operation that is strictly regulated to maintain food safety, hygiene, animal welfare and clean working conditions. Current slaughter methods are categorized as conventional or carried out according to specific ritual requirements (Havinga, 2010). According to the Islamic slaughter method (halal), the animals are killed by cutting their jugular veins, carotid arteries, oesophagus and trachea with a single swipe of sharp knife for decreasing the pain that animals would incur (Department of Standards Malaysia, 2009). Stunning animals in halal slaughter is a matter of debate. JAKIM (2011) stated that before accepting the stunning procedure in halal slaughter, the procedure should fulfil three main 
requirements. First, the stunning instruments should be used under the supervision of a trained Muslim or slaughter man, and the procedure must be monitored regularly by an experienced Islamic authority. Second, the stunning procedure must be temporary, so that it neither kills nor injures the animal. Lastly, equipment used to stun pigs must never be used for halal animals. Head-only electrical stunning using water bath stunners is widely employed by halal commercial poultry processing plants in Malaysia. However, some Muslim scholars reject pre-slaughter stunning because the procedure is unnecessary, against religious rules, or causes suffering to animals because of the pain it may inflict (Anil, 2012). Electrical stunning has been associated with several welfare issues such as inversion and live shackling, and pre-stun shocks of the birds (Raj \& Tserveni-Gousi, 2000).

In the Islamic religion, a lot of importance is given to the humane treatment of animals, especially prior to and during slaughter. However, halal slaughter without stunning is related to delayed loss of consciousness (Gregory et al., 2010) and stimulation of noxious chemicals in the period after the neck incision (Gibson, 2009). Though many studies have investigated the effect of the electrical stunning and slaughter on the poultry meat quality (Hillebrand et al., 1996; Goksoy et al., 1999; Lambooij et al., 1999; Contreras \& Beraquet 2001), little information is available with regard to the effect of the presence or absence of the electrical stunning technique on animal stress hormones, when it was combined with the halal slaughter method. Such information is important to highlight the welfare of poultry during processing.

Rules and regulations are in place to ensure that the slaughter of any animal for food production or further processing should be conducted in a humane manner, with the goal of not eliciting unnecessary pain and suffering to the animal (Wenner, 2011; Leary et al., 2013). The methods employed for slaughtering affects the welfare of animals. Chickens are shackled to facilitate stunning and slaughter. However, vigorous struggling and wing flapping are especially evident when they are inverted and suspended on shackles and this may result in pain and distress (Wotton \& Wilkins, 2004). This problem may be exacerbated in birds with leg disorders. Kannan et al. (1997), Debut et al. (2005) and Bedanova et al. (2007) reported that shackling and moving on the shackle line was stressful to broilers, as indicated by elevated corticosterone (CORT) concentration and heterophil to lymphocyte ratios. In mammalian species, circulating levels of cortisol, adrenaline (AD) and noradrenaline (NAD) are widely used as stress indicators prior to and during slaughter (Warriss, 2010). A head-only electrical stunning method, which uses a water bath, in which the electrical current is passed across the bird's head instead of the whole body, results in a better stun quality that does not affect the quality of the carcass as the current does not lead to skeletal muscle contractions in the bird's body (Raj et al., 2001; Raj \& O'Callaghan, 2004; Lambooij et al., 2010). Although the main purpose of stunning is to eliminate animal suffering during slaughter, an increase in the concentrations of stress-linked hormones has been reported in horses (Micera et al., 2010), lambs (Pearson et al., 1977; Linares et al., 2008), pigs (Hambrecht et al., 2004; Nowak et al., 2007) and rabbits (Nakyinsige et al., 2014) that are subjected to various stunning techniques. Thus, the objective of this study was to evaluate the effect of shackling and halal slaughter with head-only electrical stunning (ES) using a water bath or no stunning (NS) on plasma levels of the AD, NAD, and CORT in broiler chickens.

\section{Materials and Methods}

The study was carried out according to the animal ethics guidelines from the Research Policy of Universiti Putra Malaysia. The study was conducted in a commercial poultry processing plant in Johore, West Malaysia. Male and female broiler chickens (Cobb 500), 38 days old, from a commercial farm in Johore, Malaysia, were placed in plastic crates $(0.80 \times 0.60 \times 0.31 \mathrm{~m})$ at 10 birds per crate, and transported for 2.5 hours on an open truck. The ambient temperature during transportation was 25 to $27^{\circ} \mathrm{C}$. Upon arrival at a commercial processing plant, 50 male broiler chickens (2.2 - $2.5 \mathrm{~kg}$ ) were randomly selected from the flocks that were delivered, transferred to five crates (10 birds per crate) and held in a lairage for 2 to 3 hours. Each of the five crates was used for blood collection at various sampling points.

Prior to slaughter, baseline blood samples $(3 \mathrm{~mL})(\mathrm{P} 1$, the first sampling point for both ES and NS chickens) were collected from the wing vein of 10 birds at the lairage (crate 1) using ethylenediaminetetraacetic acid tubes. Next, further blood samples were taken from 10 birds (crates 2 through 5) according to each action namely shackling for 18 - 25 seconds (wing vein) (P2, second sampling point for both ES and NS chickens), stunning, within 15 seconds following stunning (wing vein) (P3, third sampling point for ES chickens). Following neck cut, blood samples were collected while the blood was flowing freely from the cut wound of ES (P4, fourth sampling point for ES chickens) and the cut wound of NS (P5, the third sampling point for NS chickens) chickens. Blood samples (during slaughter) from the ES (P4) and NS (P5) birds were collected alternately. As such, different chickens were sampled on each occasion. Once obtained, blood tubes were maintained at $4{ }^{\circ} \mathrm{C}$ and centrifuged at $3000 \mathrm{rpm}$ for 15 min within the first hour of sampling. The recovered plasma fraction was divided into aliquots and stored at $-80{ }^{\circ} \mathrm{C}$ until analysis. Plasma levels of AD and NAD were determined using the appropriate ELISA kits (Cusabio Biotech Co., Ltd., 
Baltimore, MD, USA). Plasma CORT concentration was measured with an ELISA kit (IDS, Boldon, UK). All samples were measured in duplicates. All chickens were slaughtered according to the halal method as outlined in MS1500:2009 (Department of Standards Malaysia, 2009). The birds were slaughtered by a Halal licensed slaughterman by severing the carotid arteries, jugular veins, trachea and oesophagus. Individual broilers were shackled upside down (both feet) on a moving conveyor and subjected to head-only electrical water bath stunning. An estimated current of $240 \mathrm{~mA}$ was delivered for 5 seconds to each bird using $400 \mathrm{~Hz}$ sine wave AC (Raj \& O'Callaghan, 2004), and the voltage was $50 \mathrm{~V}$. Five birds at a time were stunned in the water bath. The absence of corneal reflex, spontaneous eye blinking, and response to comb pinching were used as indicators of effective stunning (Girasole et al., 2016).

All statistical analyses were carried out using $S A S \otimes$ software (Statistical Analysis System, SAS Institute Inc., Cary, NC, USA) (SAS, 2005). The AD, NAD and CORT data were subjected to one-way ANOVA using the GLM procedure, where the various sampling points were fixed as the main effect. Prior to analyses, the $A D$ and $N A D$, and CORT data were transformed to common logarithm and square root, respectively. Comparison between means was done by Tukey's test. The level of significance is considered at $P \leq 0.05$.

\section{Results and Discussion}

Table 1 shows the effects of shackling, electrical stunning, and halal slaughtering method on plasma concentrations of the $A D, N A D$, and CORT in broiler chickens. The AD values at P1, P2, P4, and P5 were similar. However, the P3 value was significantly $(P=0.0122)$ higher than the other sampling points. Sampling point had no significant effect on NAD $(P=0.4113)$. The CORT at P3 was significantly $(P<0.0001)$ higher than the other sampling points. The CORT values at P4 and P5 were similar, and both values were significantly $(P<0.0001)$ higher compared with CORT values at P1 and P2. The CORT values at P1 and P2 were similar.

Table 1 Mean $( \pm$ SE) plasma concentrations of adrenaline, noradrenaline and corticosterone as affected by shackling, electrical stunning and halal slaughtering method in broiler chickens

\begin{tabular}{lcccc}
\hline Sampling point & N & Adrenaline & Noradrenaline & Corticosterone \\
\hline After lairaging (P1) & 10 & $514^{\mathrm{b}} \pm 19.09$ & $1801 \pm 84.48$ & $5.900^{\mathrm{c}} \pm 0.19$ \\
After shackling (P2) & 10 & $478^{\mathrm{b}} \pm 8.910$ & $1621 \pm 85.37$ & $5.520^{\mathrm{c}} \pm 0.50$ \\
After stunning (P3) & 10 & $651^{\mathrm{a}} \pm 76.14$ & $1671 \pm 72.58$ & $19.12^{\mathrm{a}} \pm 1.31$ \\
After slaughtering of stunned chickens (P4) & 10 & $455^{\mathrm{b}} \pm 19.97$ & $1511 \pm 102.9$ & $15.46^{\mathrm{b}} \pm 1.20$ \\
After slaughtering of no stun chickens (P5) & 10 & $511^{\mathrm{b}} \pm 47.70$ & $1504 \pm 72.58$ & $14.14^{\mathrm{b}} \pm 1.25$ \\
$P$-values & & 0.0122 & 0.4113 & $<.0001$ \\
\hline
\end{tabular}

${ }^{\text {a-c }}$ Column means with different superscripts differ significantly at $P<0.05$

In the present study, the $A D, N A D$ and CORT were not significantly affected after shackling. According to Bedanova et al. (2007), the stressfulness of shackling was dependent on the duration. Birds in the present study were shackled for 18 - 25 seconds. Shackling birds for less than 60 seconds did not influence CORT (Bedanova et al., 2007). The authors reported four- and ninefold increases in CORT after 60 seconds and 120 seconds of shackling, respectively.

In their study, Nowak et al. (2007) suggested analysing the sticking blood as it could help the investigators to determine the pain incurred by the animals, as it provides vital information regarding the degree and type of stress that the animal endured during its stunning and neck-cutting procedure. Circulating levels of $A D, N A D$ and CORT hormones are typically measured as key indicators of stress response to various stunning and slaughter procedures for cattle (Zulkifli et al., 2014), lambs (Linares et al., 2008), horses (Micera et al., 2010), rabbits (Nakyinsige et al., 2014), and pigs (Althen et al., 1977). The stunning procedure is implemented primarily to remove distress in the animal during the slaughtering process. However, the stunning process itself can produce unwanted physiological stress reactions in the animals. Pearson et al. (1977) noted a significant increase in catecholamine in lambs that were stunned electrically prior to slaughter. Linares et al. (2008) reported that both electric and gas stunning evoked catecholamine and cortisol reactions in lambs. The present findings agree with those of with earlier works (Troeger \& 
Woltersdorf, 1991; Hambrecht, 2004; Linares et al., 2008) in mammalian species that stunning elevated AD and that a hormone is a sensitive index for assessing post-stunning stress. However, the increase in the levels of the hormones could be attributed to the stunning technique itself rather than an indication of the amount of stress. In the present study, stunning elevated the level of the AD but not NAD. Broom \& Johnson (1993) stated that AD levels were significantly affected by psychological stress, while NAD levels were generally related to physical distress. Thus, the lack of NAD reaction to ES may suggest that the electrical stunning itself was not physiologically stressful to the chickens. An effective stunning technique should result in instantaneous unconsciousness in an animal before the pain associated with the stunning method can be registered (Grandin, 1994).

The present findings showed that head-only electrical water bath stunning resulted in a significant elevation in CORT. Similarly, work in pigs (Forslid \& Augustinsson 1988; Warriss et al., 1994; Hambrecht et al., 2004) showed that electrical stunning increased serum levels of cortisol. Working with mechanically stunned horses, Micera et al. (2010) indicated that increases in circulating levels of cortisol were associated more with stress/excitement/hardship reaction than as a weariness function. It has been suggested that the psychological component of the stressor was the main determinant of glucocorticoid response rather than the situation per se (Veissier \& Boissy 2007). Therefore, other physiological indicators could be more reliable than CORT to measure the consequence of the technique of electrical stunning itself ${ }^{`}$ on stress response.

Many welfare concerns are associated with the halal slaughter technique, which does not involve stunning (Aghwan et al., 2016). For example, the halal slaughter process may result in a longer time for the animal to lose consciousness, which may result in suffering. The duration of pain an animal experienced before death could be influenced by the time it took to lose consciousness (Gregory et al., 2010). Slaughtering without stunning may prolong brain function loss before death (Gregory, 2008). In their study, Anil et al. (2006) observed that the animals subjected to religious slaughter without stunning had to endure a lot of pain and distress during and after their neck-cutting and slaughter procedure before they lost their brain activity. In the present study, the AD and NAD of both ES and NS birds at P4 and P5, respectively, were similar to those at P1 and P2. Thus, as measured by $A D$ and NAD, there is little indication that halal slaughter was stressful to either ES or NS birds. According to Shaw \& Tume (1992), the measurement of catecholamine in post-slaughter blood samples in cattle could be of limited value as electrical and mechanical stunning may both result in an upsurge in these hormones. In the present study, AD, but not NAD of ES birds was elevated at P3, but declined at P4. Work in sheep (Linares et al., 2008) suggested that electrical stunning elevated both AD and NAD significantly.

The findings of this study support the work in sheep (Purchas, 1973), cattle (Dunn, 1990), and pigs (Gregory et al., 1987) that corticosteroid levels were elevated in post-slaughter blood samples. The authors noted that neck cut elevated CORT in both NS and ES compared with values at P1. Shaw \& Tume (1992) reviewed work in mammalian species, and concluded that measurement of cortisol in blood samples collected at sticking might provide information on pre-slaughter stress. Tume \& Shaw (1992) compared cortisol levels in blood samples collected from cattle during exsanguination at research and commercial abattoirs. The authors noted that the commercial abattoir group had elevated mean cortisol values compared with those collected at the research abattoir, and attributed the findings to stresses associated with transportation and introduction to a novel environment. Hence, in the present study, the elevated CORT at P4 in ES birds could be attributed to the surge in hormonal values following stunning (P3). However, there is no clear explanation for the higher CORT that was noted at P5 compared with P1 and P2. Earlier work in avian species (Schoech et al., 1999; Romero \& Reed, 2005) suggested that CORT did not increase in the first two minutes after the imposition of a stressor. Thus, it appears that the elevated CORT at P5 in NS birds could not be attributed to the neck cut procedure. On a cautionary note, the concentrations of hormones that were measured are influenced by a large number of physiological conditions, such as state of hydration or psychological stress, and not only pain and distress. Other methodologies, such as the use of an electroencephalogram, are required to allow a more direct assessment of the stimuli experienced during neck cut (Mellor et al., 2009) in poultry.

\section{Conclusions}

It can be concluded that shackling for less than $30 \mathrm{sec}$, as measured by plasma levels of the $A D$, NAD, and CORT did not elicit a physiological stress response in broilers. The present results confirmed earlier studies in mammalian species that stunning may elevate blood NAD and CORT concentrations. The current results reveal that halal slaughter with or without stunning had negligible influence on physiological stress response in broilers. 


\section{Acknowledgements}

This work was supported by the Ministry of Higher Education, Malaysia, under the Fundamental Research Grant Scheme [Project no.: 02-02-13-1307FR/5524388].

\section{Authors' Contributions}

IZ, ZK, AQS \& YMG conceived and designed the experiments; IZ, ZK, AQS, YMG, AJ \& ZZ performed the experiments; IZ, EAA \& ZK analysed the data; IZ \& ZK drafted the manuscript; and IZ, ZK, EAA \& AQS revised the manuscript.

\section{Conflict of Interest Declaration}

No potential conflict of interest was reported by the authors.

\section{References}

Aghwan, Z.A., Bello, A.U., Abubakar, A.A., Imlan, J.C. \& Sazili, A.Q., 2016. Efficient halal bleeding, animal handling, and welfare: A holistic approach for meat quality. Meat Sci. 121, 420-428.

Althen, T.G., Ono, K. \& Topel, D.G., 1977. Effect of stress susceptibility or stunning method on catecholamine levels in swine. J. Anim. Sci. 44, 985-989.

Anil, M.H., 2012. Religious slaughter: A current controversial animal welfare issue. Anim. Front. 2, 64-67.

Anil, M.H., Yesildere, T., Aksu, H., Matur, E., McKinstry, J.L., Weaver, H.R., Erdogan, O., Hughes, S. \& Mason, C., 2006. Comparison of Halal slaughter with captive bolt stunning and neck cutting in cattle: Exsanguination and quality parameters. Anim. Welf. 15, 325-330.

Bedanova, I., Voslarova, E., Chloupek, P., Pistekova, V., Suchy, P., Blahova, J., Dobsikova, R. \& Vecerek, V., 2007. Stress in broilers resulting from shackling. Poult. Sci. 86, 1065-1069.

Broom, D.M. \& Johnson, K.G., 1993. Stress and Animal Welfare. Kluwer Academic, Dordrecht, Netherlands.

Contreras, C.C. \& Beraquet, N.J., 2001. Electrical stunning, hot boning, and quality of chicken breast meat. Poult. Sci. 80, 501-507.

Debut, M., Berri, C., Arnould, C., Guemene, D., Santé-Lhoutellier, V., Sellier, N., Baéza, E., Jehl, N., Jego, Y. \& Beaumont, C., 2005. Behavioural and physiological responses of three chicken breeds to pre-slaughter shackling and acute heat stress. Br. Poult. Sci. 46, 527-535.

Department of Standards Malaysia, 2009. MS 1500: Halal food - production, preparation, handling and storage - general guidelines (second revision); Accessed 21 August 2016. Available from: https://law.resource.org/pub/my/ibr/ms.1500.2009.pdf.

Dunn, C.S., 1990. Stress reactions of cattle undergoing ritual slaughter using two methods of restraint. Vet. Rec. 126, 522-525.

Forslid, A. \& Augustinsson, O., 1988. Acidosis, hypoxia and stress hormone release in response to one-minute inhalation of $80 \% \mathrm{CO}_{2}$ in swine. Acta Physiol. Scand. 132, 223-231.

Gibson, T.J., 2009. Electroencephalographic responses of calves to the noxious sensory input of slaughter by ventral neck incision and its modulation with non-penetrative captive bolt stunning: A thesis presented in partial fulfilment of the requirements of the degree of Doctor of Philosophy in Physiology, Massey University, Palmerston North, New Zealand.

Girasole, M., Marrone, R., Anastasio, A., Chianese, A., Mercogliano, R. \& Cortesi, M.L., 2016. Effect of electrical water bath stunning on physical reflexes of broilers: evaluation of stunning efficacy under field conditions. Poult. Sci. 95, $1205-1210$.

Goksoy, E.O., McKinstry, L.J., Wilkins, L.J., Parkman, I., Phillips, A., Richardson, R.I. \& Anil, M.H., 1999. Broiler stunning and meat quality. Poult. Sci. 78, 1796-1800.

Grandin, T., 1994. Euthanasia and slaughter of livestock. J. Am. Vet. Med. Assoc. 204, 1354-1354.

Gregory, N.G., 2008. Animal welfare at markets and during transport and slaughter. Meat Sci. 80, 2-11.

Gregory, N.G., Moss, B.W. \& Leeson, R.H., 1987. An assessment of carbon dioxide stunning in pigs. Vet. Rec. 121, 517518.

Gregory, N.G., Fielding, H., Von Wenzlawowicz, M. \& Von Holleben, K., 2010. Time to collapse following slaughter without stunning in cattle. Meat Sci. 85, 66-69.

Hambrecht, E., Eissen, J.J., Nooijen, R.I.J., Ducro, B.J., Smits, C.H.M., Den Hartog, L.A. \& Verstegen, M.W.A., 2004. Preslaughter stress and muscle energy largely determine pork quality at two commercial processing plants. $\mathrm{J}$. Anim. Sci. 82, 1401-1409.

Havinga, T., 2010. Regulating halal and kosher foods: different arrangements between state, industry and religious actors. Erasmus L. Rev. 3, 241-255.

Hillebrand, S., Lambooy, E. \& Veerkamp, C., 1996. The effects of alternative electrical and mechanical stunning methods on hemorrhaging and meat quality of broiler breast and thigh muscles. Poult. Sci. 75, 664-671.

JAKIM, 2011. Malaysian protocol for the halal meat and poultry productions; Accessed 15 November. Available from http://www.halal.gov.my/v2/cms/content/editor/files.

Kannan, G., Heath, J.L., Wabeck, C.J. \& Mench, J.A., 1997. Shackling of broilers: effects on stress responses and breast meat quality. Br. Poult. Sci. 38, 323-332.

Lambooij, E., Pieterse, C., Hillebrand, S.J. \& Dijksterhuis, G.B., 1999. The effects of captive bolt and electrical stunning, and restraining methods on broiler meat quality. Poult. Sci. 78, 600-607.

Lambooij, E., Reimert, H.G.M. \& Hindle, V.A., 2010. Evaluation of head-only electrical stunning for practical application: Assessment of neural and meat quality parameters. Poult. Sci. 89, 2551-2558. 
Leary, S. L., Underwood, W., Anthony, R., Gwaltney-Brant, S., Poison, A. \& Meyer, R., 2013. AVMA guidelines for the euthanasia of animals: 2013 edition. Available: https://www.avma.org/KB/Policies/Documents/euthanasia.pdf. Accessed 4 April 2018.

Linares, M.B., Bórnez, R. \& Vergara, H., 2008. Cortisol and catecholamine levels in lambs: Effects of slaughter weight and type of stunning. Livest. Sci. 115, 53-61.

Mellor, D.J, Gibson, T.J. \& Johnson, C.B., 2009. A re-evaluation of the need to stun calves prior to slaughter by ventralneck incision: an introductory review. N. Z. Vet. J. 57, 74-76.

Micera, E., Albrizio, M., Surdo, N.C., Moramarco, A.M. \& Zarrilli, A., 2010. Stress-related hormones in horses before and after stunning by captive bolt gun. Meat Sci. 84, 634-637.

Nakyinsige, K., Sazili, A.Q., Zulkifli, I., Goh, Y.M., Bakar, F.A. \& Sabow, A.B., 2014. Influence of gas stunning and halal slaughter (no stunning) on rabbits welfare indicators and meat quality. Meat Sci. 98, 701-708.

Nowak, B., Mueffling, T.V. \& Hartung, J., 2007. Effect of different carbon dioxide concentrations and exposure times in stunning of slaughter pigs: Impact on animal welfare and meat quality. Meat Sci. 75, 290-298.

Pearson, A.J., Kilgour, R., De, L.H. \& Payne, E., 1977. Hormonal responses of lambs to trucking, handling and electric stunning. N. Z. Soc. Anim. Prod. 37, 243-248.

Purchas, R.W., 1973. The response of circulating cortisol levels in sheep to various stresses and to reserpine administration. Aust. J. Biol. Sci. 26, 477-490.

Raj, A.B.M. \& O'Callaghan, M., 2004. Effect of amount and frequency of head-only stunning currents on the electroencephalogram and somatosensory evoked potentials in broilers. Anim. Welf. 13, 159-170.

Raj, A.B.M., Wilkins, L.J., O'Callaghan, M. \& Phillips, A.J., 2001. Effect of electrical stun/kill method, interval between killing and neck cutting and blood vessels cut on blood loss and meat quality in broilers. Br. Poult. Sci. 42, 51-56.

Raj, M. \& Tserveni-Gousi, A., 2000. Stunning methods for poultry. Worlds Poult. Sci. J. 56, 291-304.

Romero, L.M. \& Reed, J.M., 2005. Collecting baseline corticosterone samples in the field: Is under 3 min good enough? Comp. Biochem. Physiol. A Mol. Integr. Physiol. 140, 73-79.

SAS, 2005. SAS/STAT software, version 9.4. SAS Inst. Inc., Cary, NC, USA.

Schoech, S.J., Ketterson, E.D. \& Nolan Jr, V., 1999. Exogenous testosterone and the adrenocortical response in darkeyed juncos. Auk. 64-72.

Shaw, F.D. \& Tume, R.K., 1992. The assessment of pre-slaughter and slaughter treatments of livestock by measurement of plasma constituents - a review of recent work. Meat Sci. 32, 311-329.

Troeger, K. \& Woltersdorf, W., 1991. Gas anesthesia of slaughter pigs. Fleischwirtsch Int. 4, 43-49.

Veissier, I. \& Boissy, A., 2007. Stress and welfare: Two complementary concepts that are intrinsically related to the animal's point of view. Physiol. Behav. 92, 429-433.

Warriss, P.D., 2010. Meat science-An introductory text (2nd edition). Chapter 10, Animal Welfare, pp. 151-165. CABI, Cambridge, Massachusetts, USA.

Warriss, P.D., Brown, S.N., Adams, S.J.M. \& Corlett, I.K., 1994. Relationships between subjective and objective assessments of stress at slaughter and meat quality in pigs. Meat Sci. 38, 329-340.

Wenner, C. A., 2011. Judicial review and the human treatment of animals. NYUL Rev. 86, 1630-1668. Available: https://www.google.com/search?client=safari\&rls=en\&q=Wenner,+C.+A.,+2011.+Judicial+review+and+the+huma n+treatment+of+animals.\&ie $=U T F-8 \& o e=U T F-8$

Wotton, S. \& Wilkins, L., 2004. In: C.A. Weeks \& A. Butterworth (eds). Measuring and Auditing Broiler Welfare. Chapter 15, Primary processing of poultry. pp. 161-180. CABI, Cambridge, Massachusetts, USA.

Zulkifli, I., Goh, Y.M., Norbaiyah, B., Sazili, A.Q., Lotfi, M., Soleimani, A.F. \& Small, A.H., 2014. Changes in blood parameters and electroencephalogram of cattle as affected by different stunning and slaughter methods in cattle. Anim. Prod. Sci. 54, 187-193. 